\title{
Política como interpretación *
}

\author{
Ugo PERONE
}

\section{Breve introducción biográfica}

Este artículo no pretende describir la situación política italiana. Por un lado ésta es tan compleja (o quizá confusa) que resulta dificil desenvolverse en ella; por otro, debido a su plasticidad, a la posibilidad que aún existe de orientarla para conseguir distintos resultados, es prácticamente imposible limitarse a describir la situación actual sin intervenir. Mi contribución será, por tanto, ésta: una intervención que surge del interior de esta situación política; una intervención que sabcmos parcial, condicionada por una serie de opciones que la preceden pero que, sin embargo, se esfuerza por reflexionar sobre esa misma expe. riencia política vivida.

Para ser honesto con los lectores, considero un deber ofrecer, a título de premisa, unos datos biográficos que ayuden a contextualizar lo que diré.

Me considcro un filosofo temporalmente dedicado a la política. Para mi, el compromiso filosófico, de forma profesional, precede, incluso en términos de valor, al compromiso político. Este ha surgido - sin buscarlo ni quererlo- como una respucsta excepcional a una situación excepcional. La profunda crisis que atraviesa el pais, el enjuiciamicnto de una gran parte de la anterior clase política a causa de los hechos de Tangentópolis ha abierto, especialmen- te en las elecciones municipales de hace dos años, una puerta a la participación política directa de los representantes de la llamada socicdad civil. En muchos aspectos, parecía que era un momento mágico, que ponía al alcance de la mano otro modo de hacer política, una forma que implicara la atribución temporal de cse servicio para la colectividad a quien en su propio campo hubiese dado prucba de su capacidad.

Un libro de Primo Levi, con cl sugestivo título asi no ahora, cuándo?, me sirvió de guía entonces para tomar esa decisión. Si no ahora, ¿cuándo someter a análisis político las esperanzas y las expectativas dc

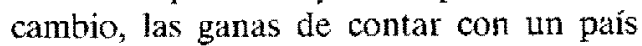
normal (Gutópico?), en el que se pase de la vida privada a la colectiva, del trabajo profesional al político en un mutuo enriquecimiento? Nació así en Turín, alrededor de la figura de Valentino Castellani, hombre arraigado en la experiencia cristiana, sin dogmatismos, comprometido políticamente pero sin estar involucrado con la anterior clase política, una coalición multicultural (socialista, laica, católica) de homines novi de la sociedad civil que se proponían llevar a cabo un modelo de acción política en la cual las diferencias culturales de las distintas procedencias, en lugar de transformarse en barrera ideológica, sirvieran de estímulo al intercambio y a una actuación política en la que demo-

\footnotetext{
* Traducción de Gaia Ronci.
} 
cráticamente los elementos diferenciadores adquirieran un nuevo valor en un proyecto y una síntesis más avanzados. Desde el punto de vista de los grupos políticos se trata de una coalición de izquierda-centro, que aspira a conjugar de forma equilibrada el binomio desarrollo-solidaridad.

Así, una vez ganadas las elecciones administrativas, acepté colaborar con el alcalde Castellani como Concejal de Recursos culturales y comunicación (cultura, educación, turismo). Ahora, a la mitad de este mandato, considero que una reflexión retrospectiva no sólo es posible, sino oportuna.

Sin embargo, es preciso hacer una última consideracion previa. El momento mágico de hace dos años se ha modificado profundamente. Las elecciones del año pasado han llevado a la victoria de la coalición de derccha, encabezada por Silvio Berlusconi, y a un gobierno de esta coalición que, a su vez, ha entrado en crisis a los pocos meses. Mientras escribo, el país se encuentra gobcrnado por un poder ejecutivo formado por técnicos, políticamente moderado, pero apoyado por una alianza parlamentaria de centro izquierda. Acapara la atención parlamentaria el debate sobre la fecha de las próximas elecciones, que parecen deparar una alternativa tajante entre centro derecha (Berlusconi) y centro izquierda (Prodi). Más allá de estas alquimias políticas, el dato que considero más relevante es que la victoria de la coalición de derecha, que había sabido presentarse a los clectores como una formación políticamente nueva, dado que estaba constituida básicamente por hombres no comprometidos con la administración anterior, ha puesto de manifiesto tales métodos y comportamientos que hacen añorar a la vieja clase política. Aún más explícitamente que éstá, la coalición de derecha está al servicio de intereses partidistas, si bien es capaz de «promocionar" su posición de forma más descarada, dis- frazándola con fáciles promesas y consignas emocionales (Fuerza Italia). En resumidas cuentas, incluso culturalmente, un claro paso atrás hacia la zafiedad y la simplificación.

«Si no ahora, cuándo» vuelve así a sonar en mi conciencia, aunque con tonos más sombríos, porque la definitiva asunción de poder por parte de este tipo de personas prorroga en el tiempo y empeora el presunto modemismo del socialismo de Craxi y además es preludio de una sociedad teleguiada, en la cual se estrechan los márgenes de la democracia de hecho, ya que no de la de derecho. De todas formas, hablando en términos filosóficos, este tipo de política, aun antes que por sus contenidos especificos, resulta inaceptable porque ha abandonado totalmente la referencia a los valores (de justicia, de verdad, etc.), para sustituirlos por el cuidado de la imagen y el control de los medios de comunicación.

\section{Novedad y política}

Las batallas politicas italianas se han librado en nombre de lo nuevo. Ya he indicado que, incluso desde un punto de vista puramente teórico, la categoría de lo nuevo es una categoría desesperadamente moderna y que elude la paradoja que lleva en sí. Lo nuevo propio de la modernidad, de hecho, es lo nuevo por lo nuevo, es decir aquel nuevo que no lo es por efecto de una diversidad, sino aquel que tiene en el hecho de ser nuevo el marchamo de la diversidad. Este tipo de nuevo que, en definitiva, está desprovisto de contenido entrana una especie de condena. En una aceleración continua, se ve expuesto a ser superado por un nuevo nuevo y así continuamente. Sin embargo, su mayor amenaza es que, por las mismas razoncs, está siendo continuamente impulsado a una renovación sólo aparente $y$, por lo tanto, 
a presentarse siempre bajo el aspecto de la novedad, con independencia absoluta de los contenidos concretos de la propuesta política. Desde este punto de vista, la categoría de la novedad se configura no sólo como típicamente moderna, sino también como extremadamente connatural de la tradición política italiana. Pensando en una novela emblemática como el Gautopardo, recordaremos que el Marqués de Salinas, típico representante de la aristocracia derrotada con la unidad de ltalia, se adhiere a una postura de absoluta y total renovación, convencido de que la mejor forma para conservar el orden antiguo es cambiarlo todo. Cambiarlo todo para que no cambie nada puede, así, entenderse como metáfora de aquel nuevo que, no teniendo contenidos propios, innova todo pero manteniendo una sustancial continuidad con el pasado, del que es en realidad la típica expresión.

$Y$ sin embargo, el anhelo de novedad contiene también la espera, confusa pero no por eso menos urgente, de algo inédito de otro orden, la expectativa de una frescura y de una moralidad que se presiente como preludio de un orden político diferente y más justo. Ahora bien, besta espera difusa y genuina encucntra su lugar en la política? O mejor, si csta novedad apareciera, itendría, en politica, el derecho a reclamar para sí como argumento y como seña de identidad decisiva el hecho de representar esta novedad? Creo que no. Es decir, considero que en política es demasiado peligroso dar un carácter absoluto y discriminante a los argumentos de valor. Y no porque la política sea sucia, sino porque la política no debe recurrir a este tipo de categorías.

Antes que el lector se apresure a reprocharme una contradicción, la expreso yo mismo. Por lo dicho se podría pensar que el rechazo a la política de la derecha italiana, ahora en mayoria, se debe a argumentos de valor: no haría referencia a valo. res de justicia y de verdad, es más, carecería totalmente de valores. Ahora se dice, en cambio, que la política no tiene que recurrir a argumentos de valor para legitimar y hacer prevalecer sus posiciones. Así que, por un lado, se afirma que una política no puede construirse sin hacer referencia a unos valores y, por cl otro, que no está legitimada a hacer apelación a ellos. De momento basta con referimos a este callejón sin salida. Tal vez lo que sigue pueda proporcionar elementos capaces de desentrañar esta dificultad sin encorsetarla en forma de contradicción.

Pero volvamos al tema de lo nuevo, del que habiamos partido. En efecto, lo nuevo se reconoce sólo después. Por eso la política es riesgo, clección, posibilidad de error. La novedad, dotada de contenido, se identifica como novedad sólo después. I a novedad no cs un argumento (del que alardear antes), sino un carácter de innovación (sobre cl que reflexionar). Si la politica abre un nuevo orden, y por lo tanto abre también posibilidades inéditas de valores sociales, esto sólo tiene valor politico en la medida en que es viable y ocurre. Es decir: no es el valor de novedad lo que cuenta como positivo, sino la efectiva innovación introducida, que confirma la opción y la elección que, por presentimiento, se ha hecho.

Apliquemos este mismo esquema a los valores. No existe una política auténtica que no esté anclada en unos valores, pero estos valores, políticamente hablando, no pueden ser utilizados ideologicamente como absolutos, sino constatados como realizados (e inchuso elcgidos previamente como realizables). La política justa no es aquella que apela al valor más alto de justicia, sino aquella que lo aplica de la mejor forma. A la inversa, sin embargo, no puede ser justa la política que teoriza el desprecio de aquel valor. La referencia al orden de los valores, por tanto, si no pucde servir como argumento, vale como comproba. 
ción; si no vale a priori, puede utilizarse perfectamente a posteriori.

¿Cuál es la razón de esta condición, que podríamos calificar de desequilibrada y tambaleante? La política es la gestion de un tiempo intermedio y valioso, una gestión desprovista de las armas de lo absoluto. No obstante tiene que ver con lo ahsoluto porque cada valor que se plasma socialmente es, a su manera, una forma absoluta, pero sin poder disponer de lo absoluto ni considerarse el modo en que cste absoluto se manifiesta históricamente.

Uno se pregunta entonces si la politica puede ser campo de filósofos, y sobre todo de filósofos con una orientación metafísica. La respuesta, quizá, está en la conciencia de que la propia filosofía, aun cuando maneja diariamente absolutos, sabe que lo hace en la forma de la finitud. Lo absoluto que se maneja no $\mathrm{es}$, de hecho, algo que se realiza en si mismo, sino la internupción del orden de la cotidianidad, una forma que se presenta en la forma de la finitud pero sustrayéndose al mero prolongarse indefinido e indiferente. El filósofo, en consecuencia, habita sicmpre espacios intermedios, incluso si en ellos vislumbra el alumbrarse de órdenes distintos. Desde este punto de vista, no hay alteridad prejudicial con la política, que es gestión de una intermediaridad, donde cl valor pueda existir.

Si me parece erróneo imaginar una política como proyecto o, peor aún, creación de lo nuevo, en cambio no me parece impropio pensar en una resistencia en favor de lo nuevo.

Retomando lo que he dicho más arriba, hay que estigmatizar, por ser fatalmente errónea, la opción por una política a la búsqueda de lo nucvo. Si se hace así, o bien se sucumbe al "nuevismo», cs decir, a una modemidad sin contenidos, a una politica del cambio incesante (e irrelcvante), a una política de la mera imagen, 0 bien pensamos, autoenganándonos, de que la política es anticipación de un verdadero orden nuevo cayendo así en un ideologismo dogmático y peligroso. La alternativa es, al fin y al cabo, entre un nuevo demasiado vacío (y por lo tanto sustituido por la imagen) y un nuevo demasiado lleno ( $y$ por lo tanto sustituido por el partido, por la ideología, por la pertenencia a una identidad). Pero todo ello es la consecuencia de un primer autoengaño: que la política tenga que ver con la producción de lo nuevo. Sin cmbargo, lo nuevo no se puede proyectar, en favor de lo nuevo sólo se puede resistir.

La política es resistencia: un paso atrás, para que otros proyectos pucdan scr. Esos proyectos son más grandes y se mantienen inexorablemente como proyectos que tienen un origen pre-político y una finalidad post-política. La política llena el cspacio intermedio; un espacio determinante ya que tiene el poder de sofocar el valor $e$ impedir el paso del origen al fin e incluso aquel - más radical si se quiere- de obstruir la percepción del origen, de condenarlo al olvido. Pero es un espacio determinante también en sentido pusitivo porque el origen y el fin sólo existen si se piensan, y sólo se pueden pensar a partir de aquel fragmento concreto que se experimenta y sobre el cual se ejerce la interpretación.

\section{Politica, representación, interpretación}

Se habla en Italia de crisis de la Izquierda. Lo cicrto es que esta crisis no ha tocado fondo, al extremo de que ya no se espere la liberación por la política. $O$ por lo menos, se duda si formular en palabras to que ya se da, de hecho, por realizado en la práctica. Y sin embargo esta tesis, tradicional de la Derecha liberal, debería ser la gran arma de la Izquierda. Porque sólo tiene derecho a expresarse así quien, al 
tener todas las razones para querer el cambio y por lo tanto para llevarlo a cabo, no es sospechoso de ideologismo. Cuando es la Derecha la que formula esta tesis, ésta se transforma en un parapeto ideológico para aceptar lo existente, pero, asumida por la Izquierda, es la salvación del dogmatismo. El cambio no nos va a salvar; sin embargo es un deber. Por otra parte, lo que se juega en política no es precisamente la salvación, sino la justicia, el bienestar, unas condiciones de vida dignas para todos, modos y tiempos de lo intermedio. Justamente porque no hay expectativa del bien absoluto, no hay ni el cinismo que nace de la espera decepcionada, ni la presunción de poseerlo. Se impone en cambio la búsqueda del bien posible y la búsqueda inflexible del mejor bien posible que, aun cuando es lo máximo que puedo alcanzar, es también lo mínimo que puedo querer.

Como hemos visto, la Derecha que llega al poder es destructiva y revolucionaria. Peor que la revolución de Izquierda, ésta, que ni siquiera puede tener grandes utopías, reduce todo a la apariencia y a la figura del lider universal de la mediocridad (cl lider del mero reflejo: aquel lider que no es otra cosa que una mera proyección a gran cscala de mis ambiciones más cotidianas y triviales).

Pero en la crisis de la Izquierda, así como en la rigidez que invade a la Derecha, subyace una convicción falsa: que la categoría clave de la política es la representación, y su corolario que un voto mayoritario autoriza no sólo a gobernar, sino también a representar a la totalidad. La política es, en realidad, ejercicio de interpretación, no de representación. En política siempre se es parte, pero se nos pide un esfuerzo - que no es mediación, sino interpretación- de universalidad. Al pretender representar, inevitablemente se prevarica $O$ en cierto modo se sustituye. $Y$ de todas formas se piensa que la relación entre lo específico de mi posición y lo universal de mi intención se basa en mi capacidad de encarnar, representándolos, los intereses universales (y los sondeos serian la confirmación empírica de ello). A la inversa, si se es conciente de que en ningún caso se va más allá de la interpretación de las expectativas más profundas de la mayoría, se es conciente del margen de ricsgo intrínseco en cada acto interpretativo y los sondeos apenas proporcionarán un indicio de confirmación o de desmentida. Es cierto que en política sólo con cifras, mayorías y minorías, puede medirse si una interpretación ha sido correcta. Sin embargo, la barrera que hay que poner a la utilización violenta de los números es una forma de participación mediante la cual la decisión final de los números llega al término de un itinerario de discusión compartida durante la cual se va formando aquel consenso que la votación pone a prueba y al final ratifica. Por tanto, lo que en última instancia - y no podía ser de otra forma- se somete a la prueba de los números, no es el agresivo e inmediato acudir a ellos, que no son argumentos, sino el habitual procedimiento de una confrontación de argumentos. Pero aquí también el número que gana no representa a la mayoria del pucblo, se limita a ratificar que el resultado interpreta de la mejor forma el sentir de la mayoría. En este sentido, como es imperativo, también la parte perdedora, también la minoría puede reconocerse, aunque de forma más incompleta y menos lograda, en la elección llevada a cabo; lo cual no hubiera podido ocurrir, en cambio, si la elección se hubiese realizado partiendo del criterio de la representación. En política, al no ser Dios, no se puede representar a la totalidad y por tanto sólo se podría representar a aquella parte de la que se es expresión (con exclusión de toda otra parte). 


\section{Configuraciones más pequeñas, sueños más grandes}

No parece una casualidad quc en Italia, en este momento, las mayores energias y cupacidad de renovación se den unidas a experiencias administrativas locales. No sc trata de localismos, sino de crisis de las grandes categorías abstractas que necesitan urgentemente ser renovadas.

La ciudad es un mosaico. Su identidad ya no es monolítica, es compleja, hecha de mundos que se entrecruzan, a menudo sin llegar a encontrarse realmente. El imperativo más urgente es hallar formas de cohesión que no se superpongan a los mundos diferentes, sino al contrario, que los respeten y los valoren y al mismo tiempo los unifiquen. No se puede ocultar la dificultad de este trabajo, ni el conflicto que le es inmanente. La identidad está en el limite, en aquel estrecho margen que crea fricción entre los mundos, que los divide y los une. Sobre eso hay que trabajar. Sin suprimir el conflicto (seria una forma de anular también la relación), pero regu- lando el conflicto. Por otra parte, la democracia no es más, al fin y al cabo, que una forma pacifica de solucionar los conflictos. Para que sca así hay que respetar las reglas: para que tenga futuro no basta con buscar en el presente y en lo inmediato el criterio para solucionar los conflictos. Es preciso algo más: un ideal, un proyecto, un sentido que induzca a dejar aparte las diferencias más inmediatas. No podemos buscar en la nación lo que nos permita ver en perspectiva y ayude a superar las diferencias. La nación es una forma de unidad discutible. Necesitamos configuraciones más pequeñas y sueños más grandes. Europa, en su momento, hubicra podido jugar ese papel. No parece que hoy pueda hacerlo. Pero, si no reaccionamos, Occidente está perdido y con él se pierde aquella forma de capacidad crítica -insoportable hasta el cansancio y el cinismo- sobre la cual, sin embargo, se ha construido nuestra civilización. El ocaso corre el riesgo de no ser una lánguida despedida, como piensan hasta personas de reconocido prestigio. Sin embargo, lo que perderíamos no carcectía de importancia.

\title{
La sociedad civil en Polonia *
}

\author{
EUGENIUSZ GÓRSKI
}

Academica de Ciencias de Polonia

En general, casi ningún país de la Europa Central y Oriental goza de una tradición importante de sociedad civil democrática. Pero Polonia es un caso peculiar: aunque ausentes durante cierto tiempo, las tradiciones sociales de ciudadanía están relativamente arraigadas en la cultura política polaca '. Polonia disfruta, en efecto, de una rica tradición constitucional y de libertad, que se remonta a su célebre Constitución del 3 de mayo de 1791.

Empero, el temor de los polacos al absolutismo político y la total supremacía de la autoorganización social a expensas de

* Traducción de Max Slern. 